\title{
Anaerobic membrane bioreactors: Are membranes really necessary?
}

\author{
David Jeison* \\ Departamento de Ingeniería Química \\ Universidad de La Frontera \\ Casilla 54-D \\ Temuco, Chile \\ Tel: 5645325453 \\ Fax: 5645325053 \\ E-mail: djeison@ufro.cl \\ Israel Días \\ Sub-Department of Environmental Technology \\ Wageningen University \\ P.O. Box 8129 \\ 6700 EV Wageningen, The Netherlands \\ Tel: 31317483339 \\ Fax: 31317482108 \\ E-mail: israel.diaz@uva.es \\ Jules B. van Lier \\ Sub-Department of Environmental Technology \\ Wageningen University \\ P.O. Box 8129 \\ 6700 EV Wageningen, The Netherlands \\ Tel: 31317483339 \\ Fax: 31317482108 \\ E-mail: Jules.vanLier@wur.nl
}

Keywords: cake layer, dynamic membrane, MBR, woven filter.

Abbreviations: AnMBR: anaerobic membrane bioreactors

MBR: membrane bioreactors

TMP: trans-membrane pressure

Membranes themselves represent a significant cost for the full scale application of anaerobic membrane bioreactors (AnMBR). The possibility of operating an AnMBR with a self-forming dynamic membrane generated by the substances present in the reactor liquor would translate into an important saving. A selfforming dynamic membrane only requires a support material over which a cake layer is formed, which determines the rejection properties of the system. The present research studies the application of self-forming dynamic membranes in AnMBRs. An AnMBR was operated under thermophilic and mesophilic conditions, using woven and non woven materials as support for the dynamic membranes. Results showed that the formation of a cake layer over the support materials enables the retention of more than $99 \%$ of the solids present in the reactor. However, only low levels of flux were achieved, up to $3 \mathrm{~L} / \mathrm{m}^{2} \times \mathrm{h}$, and reactor operation was unstable, with sudden increases in filtration resistance, due to excessive cake layer formation. Further fine-tuning of the proposed technology involves looking for conditions that can control effectively cake layer formation.
Biomass retention is a necessary feature for high rate anaerobic treatment of wastewaters, due to low growth rate of anaerobic microorganisms. Granule and biofilm formation represents the traditional way to achieve the necessary biomass retention, enabling bioreactors operation at high biomass concentrations, and therefore at high organic loading rates. However, several conditions have been identified where biofilm and granule formation does not proceed well, such as high salinity (Jeison et al. 2008) and thermophilic temperatures. In those situations where biofilm or granule formation is expected to be affected, membrane assisted physical separations can be used to achieve the essential sludge retention. Membrane bioreactors (MBR) ensure biomass retention by the application of micro or ultra filtration processes. This allows complete biomass retention and operation at high sludge concentrations (Judd, 2006). Since biomass is physically retained inside the bioreactor, there is no risk of cells washout and the conversion capacity is non-dependent on the aggregation properties of the biomass. The mayor drawback of MBR technology is related with membrane costs and fouling. Even though membrane prices have

\footnotetext{
*Corresponding author
} 
experienced an important decrease during the last decade (Judd, 2006), membranes still represent an important cost for the full scale application of anaerobic membrane bioreactors (AnMBR).

Our previous research has shown that cake layer formation is the key factor limiting the flux when operating AnMBRs, irrespective of the applied substrate, configuration (submerged or side-stream) or temperature (Jeison and van Lier, 2007a; Jeison and van Lier, 2008). Formation of a gel or cake layer over the membrane surface can determine rejection properties of the system, since the deposited layer can act as a secondary membrane. Modification of the membrane rejection properties by the formation of a fouling layer has been observed for both aerobic and anaerobic MBRs (Harada et al. 1994; Pillay et al. 1994; Choi et al. 2005). Consequently, under such conditions, the membrane itself may be no longer necessary, since solids rejection will be provided by the cake layer, which will apparently act as a self-forming dynamic membrane. Acknowledging this mechanism, the replacement of the membrane for a low cost filtration material, acting as a support over which a cake layer can be formed, is in principle feasible. Under these conditions, cake layer formation is indeed desired; however, at a level that it does not provide an excessive filtration resistance.

A dynamic membrane can also be formed by pre-coating a support material. Ye et al. (2006) pre-coated the surface of a $56 \mu \mathrm{m}$ pore size terylene filter cloth with powder-active carbon to form a dynamic membrane. Removal efficiencies comparable to those of a traditional MBR were obtained. The main disadvantage of this approach is that support filtration material has to be pre-coated with an external material. On the other hand, self-forming dynamic membranes are created by the substances existing in the liquor to be filtered, and no external materials besides the support are required.

The concept of self-forming dynamic membrane formation has been only recently researched for its application to aerobic MBRs for wastewater treatment, with promising results. Kiso et al. (2000) successfully operated an aerobic bioreactor equipped with a $100 \mu \mathrm{m}$ mesh, at fluxes over 20 $\mathrm{L} / \mathrm{m}^{2} \times \mathrm{h}$. Fluxes in the range $15-30 \mathrm{~L} / \mathrm{m}^{2} \times \mathrm{h}$ and an effluent with non detectable suspended solids were attained by Fan and Huang (2002) when operating a similar bioreactor. Positive results were also obtained by other authors, showing that dynamic self-forming membranes can be successfully used for biomass retention in aerobic bioreactors for wastewater treatment (Fuchs et al. 2005; Kiso et al. 2005; Wu et al. 2005; Chu and Li, 2006). Both woven and non-woven materials have been tested as support for the dynamic membrane formation. The use of a fouling layer as a dynamic membrane determining the rejection properties was applied by Pillay et al. (1994), for an AnMBR treating sludge. No other reports are available regarding the application of self forming dynamic membranes in AnMBRs.
The present paper describes our research on the concept of dynamic self-forming membranes and its potential applicability for the development of anaerobic AnMBRs.

\section{MATERIALS AND METHODS}

\section{Support materials for dynamic membrane formation.}

Two types of materials were used to act as a support for dynamic membrane formation. A non-woven material which is used as a spacer material to cast membranes (Norit, The Netehrlands) and polyester mesh fabrics of different pore sizes in the range 1-150 $\mu \mathrm{m}$ (Sefar B.V., The Netherlands).

\section{Batch filtration tests}

Preliminary batch filtration experiments were performed in a $300 \mathrm{~mL}$ filter holder, with an effective filtration area of $13.2 \mathrm{~cm}^{2}$. Mixing was provided by a laboratory stirrer. Filtration resistance was evaluated measuring the transmembrane pressure (TMP) by means of a pressure sensor located in the filtrate line. Filtrate was collected by a peristaltic pump, which provided the required TMP. A schematic representation of the batch filtration unit is resented in Figure 1.

\section{Continuous bioreactor operation}

Two bioreactor configurations were evaluated to determine the feasibility of self-forming dynamic membrane formation: submerged filtration module and external filtration module. Schematic representations of both configurations are presented in Figure 2 and Figure 3. Submerged configuration consisted of a $3 \mathrm{~L}$ bioreactor with the filtration module submerged in the bioreactor liquor (Figure 2). Submerged module had a filtration area of 0.0094 or $0.0188 \mathrm{~m}^{2}$, depending if one or both sides were used for filtrate collection. Biogas was recirculated to promote mixing and to avoid excessive cake layer formation. External module configuration consisted of the same $3 \mathrm{~L}$ bioreactor as for submerged configuration, connected to an external filtration module. Filtration module was composed of 2 chambers separated by the filtration material which occupied an area of $0.73 \times 0.4 \mathrm{~m}$, with an effective filtration surface of $0.0292 \mathrm{~m}^{2}$. Sludge flowed through one of the chambers, while filtrate was collected in the second chamber. Biogas was recirculated and injected in the bottom of the external filtration module (on the sludge side), to control excessive cake layer formation. Sludge circulation between the bioreactor and the external filtration module was driven by the produced gas-lift effect.

During the operation of both configurations filtrate was collected by means of a peristaltic pump that provided the required TMP. Filtration resistance was determined as a function of the TMP, which was measured by a pressure sensor located in the filtrate line. Filtrate was returned to 
the bioreactor and effluent was collected by means of the operation of an external microfiltration membrane module. The latter operation strategy was adopted to prevent sludge washout in case of malfunction of the dynamic membrane filters.

Reactors were fed with a synthetic wastewater composed by a mixture of volatile fatty acids and nutrients. Bioreactor operation was conducted under thermophilic and mesophilic conditions. Thermophilic sludge was obtained from a previously run thermophilic AnMBR (Jeison and van Lier, 2007b). For mesophilic operation, bioreactor was inoculated with crushed anaerobic granular sludge. Granules were mechanically crushed using a blender.

Bioreactor was operated under different conditions of temperature, filtering material and configuration. Table 1 describes the 3 experimental runs performed during the present research.

\section{Analysis}

TSS were determined according to standard methods (Clescerl et al. 1999). Particle size distribution was measured by laser diffraction analysis (Coulter LS230, Beckman Coulter, USA), and is presented as a volume distribution.

\section{Specific cake resistance}

During a filtration process, the flux is related with cake and membrane resistances through the resistance in series model:

$\mathrm{J}=\frac{1}{\mathrm{~A}} \frac{\mathrm{dV}}{\mathrm{dt}}=\frac{\mathrm{TMP}}{\eta} \frac{1}{\mathrm{R}_{\mathrm{M}}+\mathrm{R}_{\mathrm{C}}}$

where $\mathrm{J}$ represents the flux, A the membrane area, $\mathrm{V}$ the permeate volume, $t$ the time, $\eta$ the permeate viscosity, $R_{M}$ the membrane resistance and $R_{C}$ the cake resistance. In a dead end filtration, cake resistance is related to the specific cake resistance $(\alpha)$ through the amount of deposited particles:
$\mathrm{R}_{\mathrm{C}}=\frac{\mathrm{V}}{\mathrm{A}} \alpha \cdot \mathrm{C}$

where $\mathrm{C}$ represents the solids concentration. If $\mathrm{R}_{\mathrm{C}}$ from equation 2 is substituted in equation 1, and a constant flux is assumed, we obtain:

$\mathrm{TMP}=\frac{\eta \cdot \alpha \cdot \mathrm{C} \cdot \mathrm{J}}{\mathrm{A}} \mathrm{V}+\eta \cdot \mathrm{R}_{\mathrm{M}} \cdot \mathrm{J}$

The specific cake resistance is then determined through the evaluation of the slope of a plot of TMP against permeate volume.

Specific cake resistance was evaluated for thermophilic and mesophilic sludges applying a dead end filtration using the submerged modules inside the bioreactor. During this determination gas sparging was stopped to ensure dead end filtration conditions. TMP was followed and specific cake resistance was determined using equation 3 .

\section{RESULTS AND DISCUSSION}

\section{Preliminary batch experiments}

Since the non-woven material does not have a defined pore size, rejection properties need to be evaluated, in order to determine if the formation of a fouling layer can act as a self-forming membrane. Batch filtration experiments were performed using the same thermophilic sludge used to inoculate the thermophilic bioreactor (Run 1). Filtration was performed at a constant flux of $35 \mathrm{~L} / \mathrm{m}^{2} \mathrm{x} \mathrm{h}$ and at a TSS concentration of $17 \mathrm{~g} / \mathrm{L}$. A sample of the filtrate was obtained during the first few minutes of filtration using a new sample of non-woven material. Since formation of a cake layer takes several minutes to take place, we can assume that particles in the filtrate collected during the first few minutes of filtration are representative of those particles that can flow through the material, representing its size cut-off. Figure 4 presents the particle size distribution of the thermophilic sludge and the initial filtrate. According with Figure 4, 95\% of the particles present in this initial filtrate were below $30 \mu \mathrm{m}$. Figure 4 also shows that $47 \%$ of

Table 1. Description of the experimental runs of the AnMBR based on dynamic membrane formation.

\begin{tabular}{|l|c|c|c|}
\hline & Run 1 & Run 2 & Run 3 \\
\hline Temperature & $55^{\circ} \mathrm{C}$ & $30^{\circ} \mathrm{C}$ & $30^{\circ} \mathrm{C}$ \\
\hline Filter material & Non woven & $20 \mu \mathrm{m}$ mesh & $15 \mu \mathrm{m}$ mesh \\
\hline Configuration & submerged & submerged & external module \\
\hline Biomass concentration & $7.2 \mathrm{~g} \mathrm{TSS} / \mathrm{L}$ & $17.5 \mathrm{~g} \mathrm{TSS} / \mathrm{L}$ & $25.6 \mathrm{~g} \mathrm{TSS} / \mathrm{L}$ \\
\hline
\end{tabular}


the particles contained in the sludge were below $30 \mu \mathrm{m}$, datum that agrees with the solids concentration of the initial filtrate, which was $46.5 \%$ of the thermophilic sludge. This means that the particle size cut-off of the woven material is close to $30 \mu \mathrm{m}$, and that it can reject only $53 \%$ of the particles contained in the thermophilic sludge. Consequently, a rejection higher than the latter value during bioreactor operation will represent an indication of the formation of a dynamic self-forming membrane.

Batch filtration experiments were also conducted to select an appropriate pore size range of mesh material to be applied during continuous bioreactor operation. Several filtration experiments were performed with different pore sizes, using mesophilic anaerobic granular sludge which was previously grinded using a blender. Filtration tests were performed at a TSS concentration of $25 \mathrm{~g} / \mathrm{L}$. Batch filtrations experiments showed the impossibility to build a cake layer that would act as a dynamic membrane over meshes with pore sizes over $60-70 \mu \mathrm{m}$. A cake layer was developed in materials presenting lower pore sizes, after a period of time that depended on the mesh pore size. The cake layer build-up was registered by monitoring the increase in the filtration resistance. Figure 5 shows the resistance increase measured for meshes of 1,5 and $10 \mu \mathrm{m}$. Based on this experiments meshes with pore sizes of 15 and $20 \mu \mathrm{m}$ were used to conduct bioreactor trials.

\section{Operation of the thermophilic AnMBR with submerged module (Run 1)}

Figure 6 presents 15 days of continuous operation of the thermophilic bioreactor, operated with a submerged filtration module fitted with the non-woven material. Continuous operation of the AnMBR was characterised by an irregular filtration performance, while control of cake formation was extremely difficult. Filtration resistance and TMP rapidly increased resulting in intermittent operation cycles; with periods of filtration followed by periods with no permeate collection required to allow a TMP decrease. Applied fluxes were low, up to $3 \mathrm{~L} / \mathrm{m}^{2} \times \mathrm{h}$. However, despite these difficulties, a TSS retention over $99 \%$ was accomplished, since effluent TSS concentrations were in the range of $20 \mathrm{mg} / \mathrm{L}$. On day 15 , filtration module was extracted from the bioreactor, and its resistance was measured in clean water. Measured resistance was $1.1 \mathrm{x}$ $10^{12} \mathrm{~m}^{-1}$, a value much lower than those observed during bioreactor operation. The latter difference is a clear indication of cake layer formation during reactor operation, and it's the likely explanation for the differences in rejection of the new material with respect of that observed after 15 days of bioreactor operation.

\section{Operation of the mesophilic AnMBR (Runs 2 and 3)}

Figure 7 presents the operation of the mesophilic bioreactor, operated with the submerged filtration module fitted with $20 \mu \mathrm{m}$ mesh. Figure 8 shows the operation of the mesophilic bioreactor with the external filtration module. Similar operational problems as those observed for the thermophilic bioreactor were encountered during the operation of the mesophilic bioreactor with both submerged and external module. Operation had to be regularly interrupted to allow TMP decrease. Applied fluxes were also low, in the range $0.5-3 \mathrm{~L} / \mathrm{m}^{2} \times \mathrm{h}$. Nevertheless, biomass retention was again over $99 \%$, with typical effluent TSS concentrations close to $20 \mathrm{mg} / \mathrm{L}$.

Figure 9 presents the particle size distribution of the sludge from the mesophilic reactor. Figure 9 shows that sludge contains an important fraction of particles of sizes below the pore sizes of the filtration materials used. Then, the high solids rejection observed during the operation of the mesophilic reactor is a clear indication of the formation of a self forming dynamic membrane, which was confirmed by optical microscopic observation of the filtration material surface. Indeed, visual inspection of the external filter module, by the end of the bioreactor operation, revealed the development of a thick cake layer over the mesh, in some parts up to few millimetres.

Dead end filtration measurements were performed in order to estimate the values of the specific cake resistances for thermophilic and mesophilic sludges. Values were $6.3 \mathrm{x}$ $10^{14}$ and $3.7 \times 10^{14} \mathrm{~m} / \mathrm{kg}$, respectively. These values are one to two orders of magnitude higher than those commonly reported for aerobic MBRs (Ahmed et al. 2007; Wang et al. 2007). A high specific cake resistance hinders the application of dynamic membrane formation, since the formation of a thin layer would result in a high filtration resistance. For example, at a specific cake resistance of 3.7 x $10^{14} \mathrm{~m} / \mathrm{kg}$, a cake thickness of only $100 \mu \mathrm{m}$ will results in a filtration resistance close to $4 \times 10^{13} \mathrm{~m}^{-1}$. If the latter resistance is considered, a TMP of 0.9 bar would be required for achieving a flux of about $10 \mathrm{~L} / \mathrm{m}^{2} \times \mathrm{h}$. The filtration performances obtained during this research contrast with those reported for aerobic MBRs with dynamic membrane formation, where stable operation is reported, at moderate to high fluxes (Kiso et al. 2000; Fan and Huang, 2002). Most likely explanation for these differences is different floc morphology and particle size distribution.

Therefore, the challenge for implementing the concept of self-forming dynamic membranes in AnMBRs lays in finding the right conditions that enables the formation of this dynamic membrane, but prevents excessive filtration resistance, enabling operation at low TMP values. Anaerobic flocs morphology and size will determine the properties of the cake layer, so further study of the effect of AnMBR operational parameters over flocs properties is required. In addition, adequate control of the hydraulics in the vicinity of the filtration media can be used to prevent excessive cake layer formation. 


\section{CONCLUDING REMARKS}

From our results we conclude that dynamic membrane formation during the operation of AnMBRs is feasible, and it provides adequate biomass retention. However, reactors operation showed to be unstable, due the high specific cake resistance, which produces high filtration resistance even when a very a thin cake layer is formed. This means that control of cake layer thickness is of special importance, in order to keep TMP at moderate levels. Consequently, further fine-tuning of the proposed technology involves looking for conditions that can control cake layer formation. The study of the physical properties of anaerobic flocs developed in AnMBRs that result in a high specific cake resistance would be also of great interest.

\section{REFERENCES}

AHMED, Z.; CHO, J.; LIM, B.R.; SONG, K.G. and AHN, K.H. Effects of sludge retention time on membrane fouling and microbial community structure in a membrane bioreactor. Journal of Membrane Science, January 2007, vol. 287 , no. 2 , p. 211-218.

CLESCERL, Lenore S.; GREENBERG, Arnold E. and EATON, Andrew D. Standard Methods for the examination of water and wastewater. $20^{\text {th }}$ ed, Washington DC, APHA, 1999. 1325 p. ISBN 0-87-553235-7.

CHOI, H.; ZHANG, K.; DIONYSIOU, D.D.; OERTHER, D.B. and SORIAL, G.A. Influence of cross-flow velocity on membrane performance during filtration of biological suspension. Journal of Membrane Science, February 2005, vol. 248, no. 1-2, p. 189-199.

CHU, L.B. and LI, S. Filtration capability and operational characteristics of dynamic membrane bioreactor for municipal wastewater treatment. Separation and Purification Technology, September 2006, vol. 51, no. 2, p. 173-179.

FAN, B. and HUANG, X. Characteristics of a self-forming dynamic membrane coupled with a bioreactor for municipal wastewater treatment. Environmental Science \& Technology, December 2002, vol. 36, no. 23, p. 5245-5251.

FUCHS, W.; RESH, C.; KERNSTOCK, M.; MAYER, M.; SCHOEBERL, P. and BRAUN, R. Influence of operational conditions on the performance of a mesh filter activated sludge process. Water Research, March 2005, vol. 39, no. 5, p. 803-810.

HARADA, H.; MOMONOI, K.; YAMAZAKI, S. and TAKIZAWA, S. Application of anaerobic-Uf membrane reactor for treatment of a waste-water containing highstrength particulate organics. Water Science and Technology, 1994, vol. 30, no. 12, p. 307-319.

JEISON, David and VAN LIER, Jules B. Cake formation and consolidation: main factors governing the applicable flux in anaerobic submerged membrane bioreactors (AnSMBR) treating acidified wastewaters. Separation and Purification Technology, August 2007a, vol. 56, no. 1, p. 71-78.

JEISON, D. and VAN LIER, J.B. Thermophilic treatment of acidified and partially acidified wastewater using an anaerobic submerged MBR: Factors affecting long-term operational flux. Water Research, September 2007b, vol. 41 , no. 17 , p. 3868-3879.

JEISON, David and VAN LIER, Jules B. Anaerobic digestion and membrane filtration: A one night stand or a sustainable relationship? Water Science and Technology, 2008, vol. 57, no. 4, p. 527-532.

JEISON, David; DEL RIO, Alberto and VAN LIER, Jules B. Impact of high saline wastewaters on anaerobic granular sludge functionalities. Water Science and Technology, 2008 , vol. 57 , no. 6 , p. 815-819.

JUDD, Simon. The MBR book. Oxford, Elsevier, 2006. 325 p. ISBN 1-85-617481-6.

KISO, Y.; JUNG, Y.J.; ICHINARI, T.; PARK, M.; KITAO, T.; NISHIMURA, K. and MIN, K.S. Wastewater treatment performance of a filtration bio-reactor equipped with a mesh as a filter material. Water Research, December 2000, vol. 34 , no. 17 , p. 4143-4150.

KISO, Y.; JUNG, Y.J.; PARK, M.S.; WANG, W.H.; SHIMASE, M.; YAMADA, T. and MIN, K.S. Coupling of sequencing batch bioreactor and mesh filtration: Operational parameters and wastewater treatment performance. Water Research, December 2005, vol. 39, no. 20, p. 4887-4898.

PILLAY, V.L.; TOWNSEND, B. and BUCKLEY, C.A. Improving the performance of anaerobic digesters at wastewater treatment works: the coupled cross-flow microfiltration digester process. Water Science and Technology, 1994, vol. 30, no. 12, p. 329-337.

WANG, X.M.; LI, X.Y. and HUANG, X. Membrane fouling in a submerged membrane bioreactor (SMBR): Characterisation of the sludge cake and its high filtration resistance. Separation and Purification Technology, January 2007, vol. 52, no. 3, p. 439-445.

WU, Y.; HUANG, X.; WEN, X. and CHEN, F. Function of dynamic membrane in self-forming dynamic membrane coupled bioreactor. Water Science and Technology, 2005, vol. 51, no. 6-7, p. 107-114.

YE, M.S.; ZHANG, H.M., WEI, Q.F.; LEI, H.F.; YANG, F.L. and ZHANG, X.W. Study on the suitable thickness of a PAC-precoated dynamic membrane coupled with a bioreactor for municipal wastewater treatment. Desalination, June 2006, vol. 194, no. 1-3, p. 108-120. 


\section{APPENDIX}

\section{FIGURES}

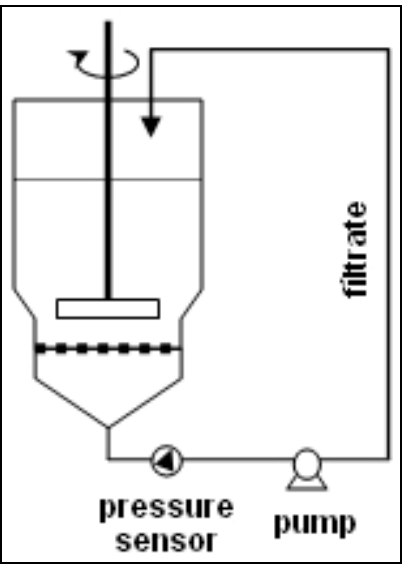

Figure 1. Schematic representation of the batch filtration set-up.

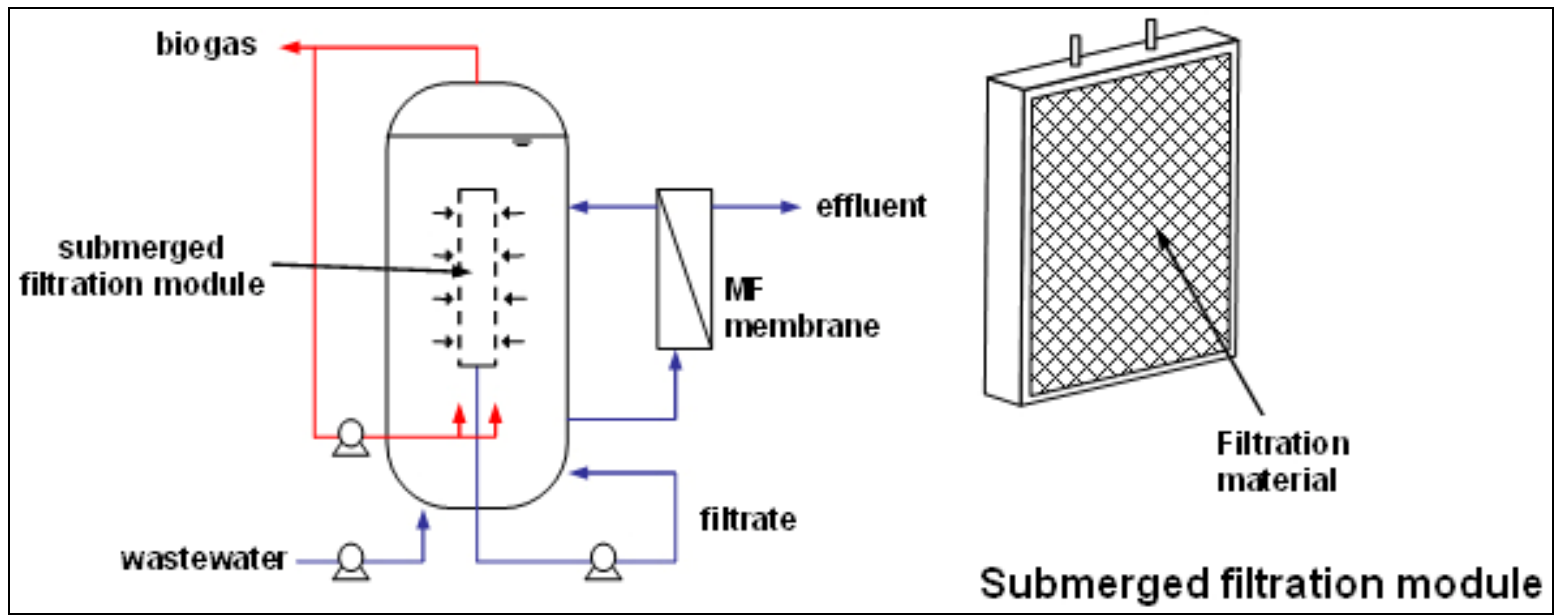

Figure 2. Schematic representation of the AnMBR with submerged filtration module for dynamic membrane formation. Blue and red lines represent liquid and gas flows, respectively. 


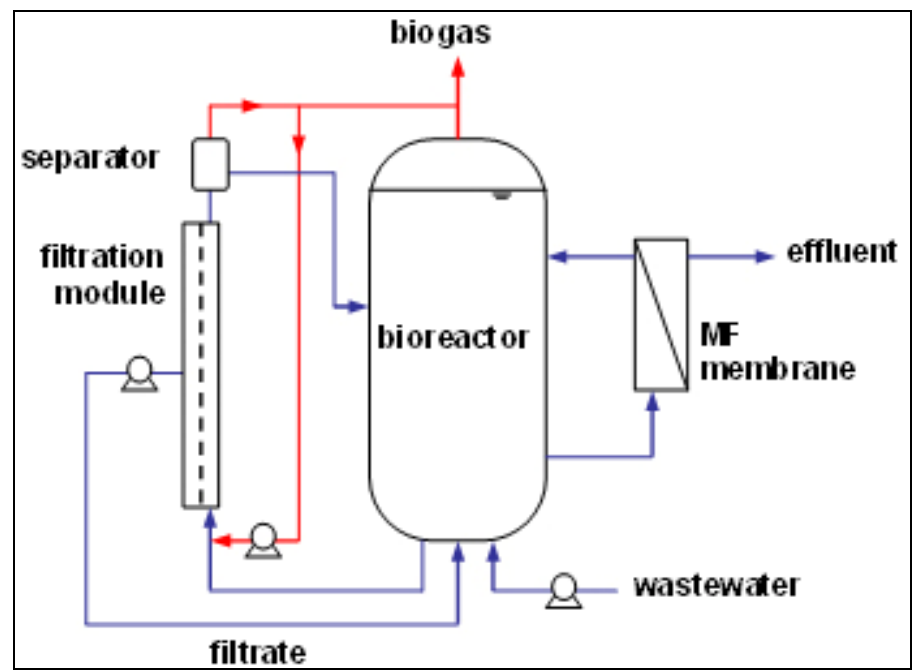

Figure 3. Schematic representation of the AnMBR with external filtration module for dynamic membrane formation. Blue and red lines represent liquid and gas flows, respectively.

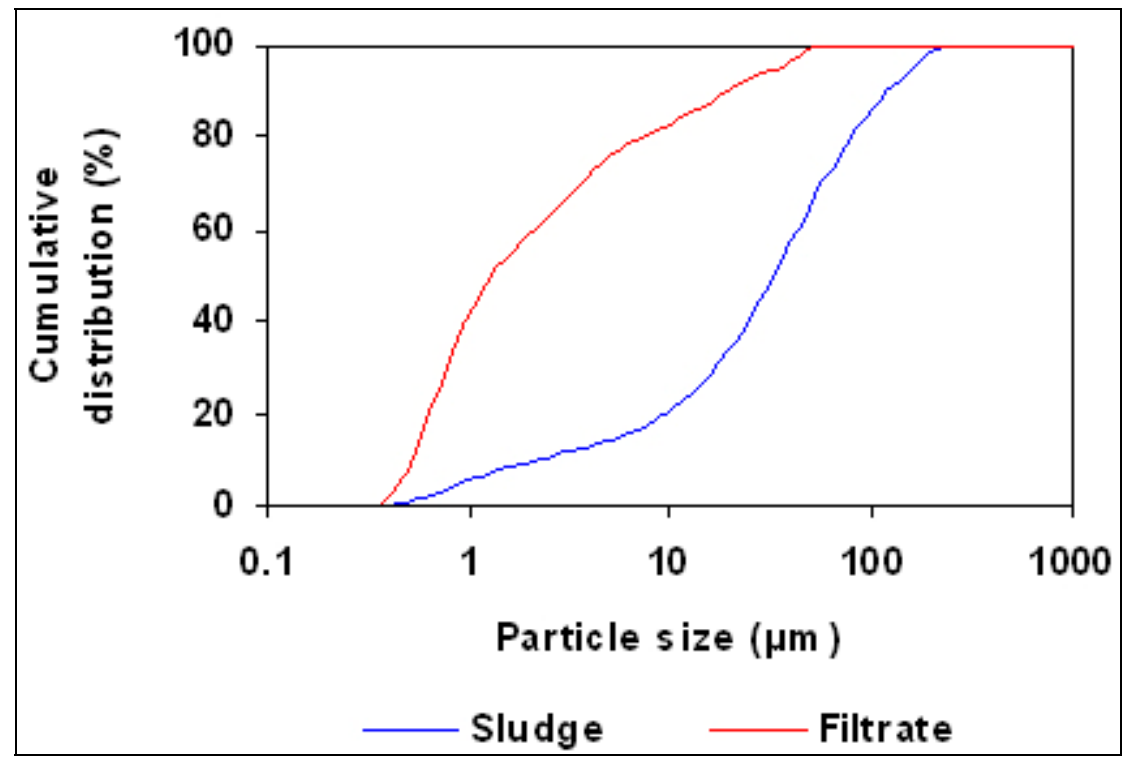

Figure 4. Cumulative particle size distribution of thermophilic sludge and the initial filtrate when filtering using non-woven material. 


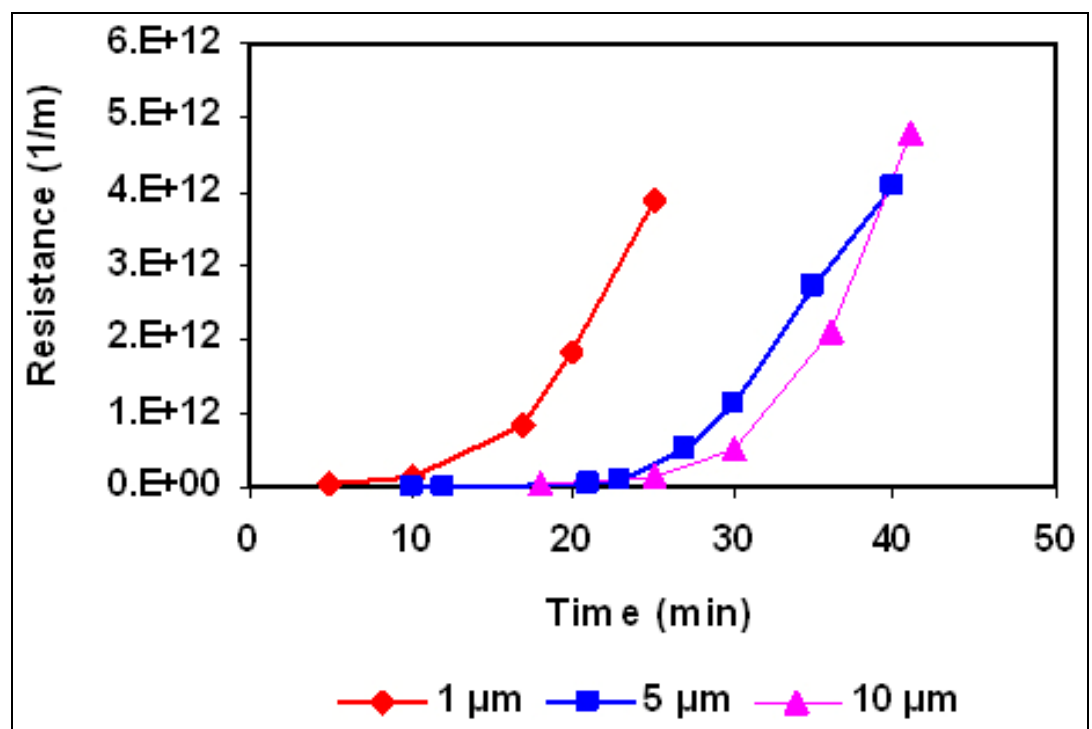

Figure 5. Filtration resistance evolution during preliminary batch filtration tests. Applied flux $25 \mathrm{~L} / \mathrm{m}^{2} \times \mathrm{h}$, sludge concentration $25 \mathrm{~g} \mathrm{TSS} / \mathrm{L}$.

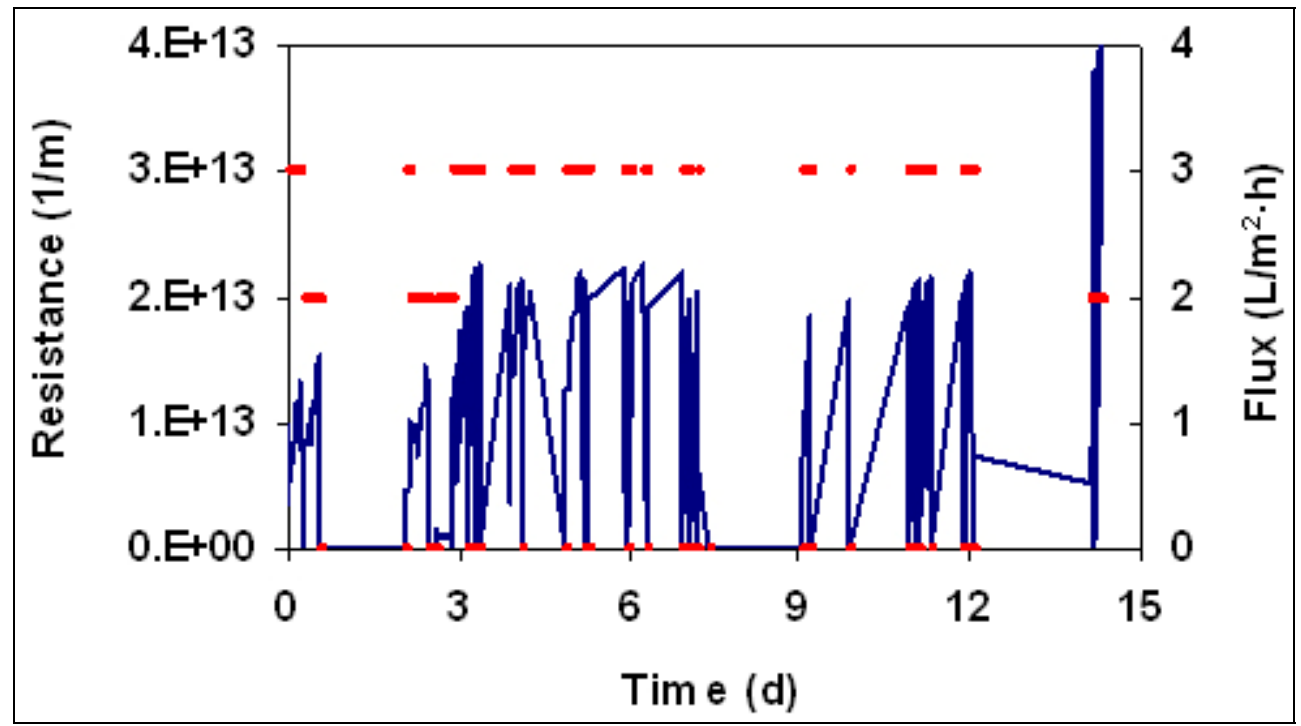

Figure 6. Applied flux and filtration resistance during the operation of the thermophilic AnMBR with submerged filtration module fitted with non-woven material. 


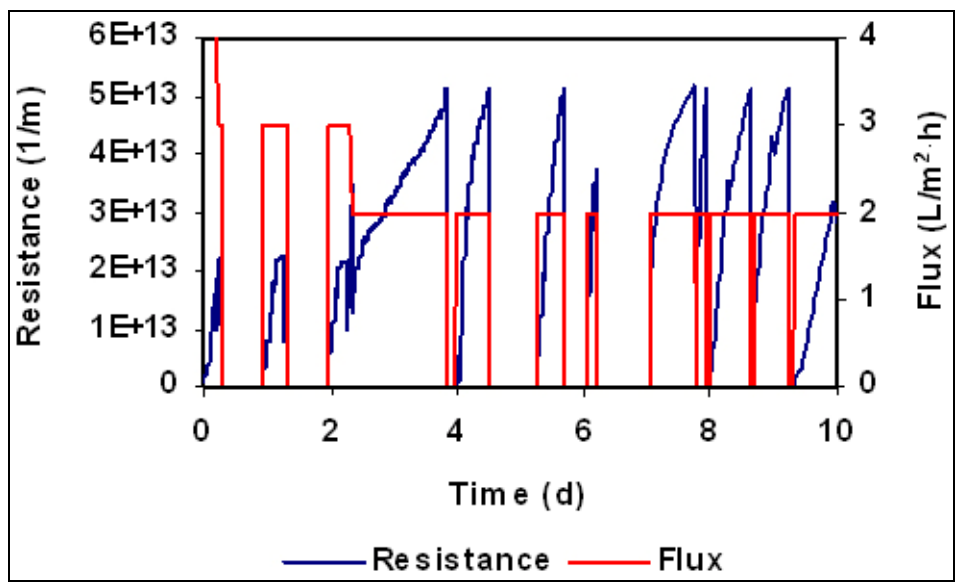

Figure 7. Applied flux and filtration resistance during the operation of the mesophilic AnMBR with submerged filtration module fitted with $20 \mu \mathrm{m}$ mesh.

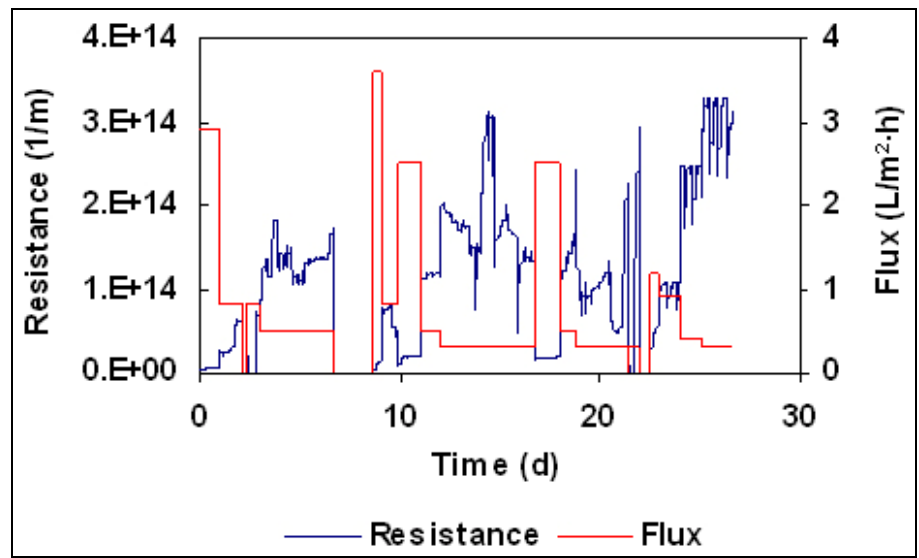

Figure 8. Applied flux and filtration resistance during the operation of the mesophilic AnMBR with external filtration module fitted with $15 \mu \mathrm{m}$ mesh.

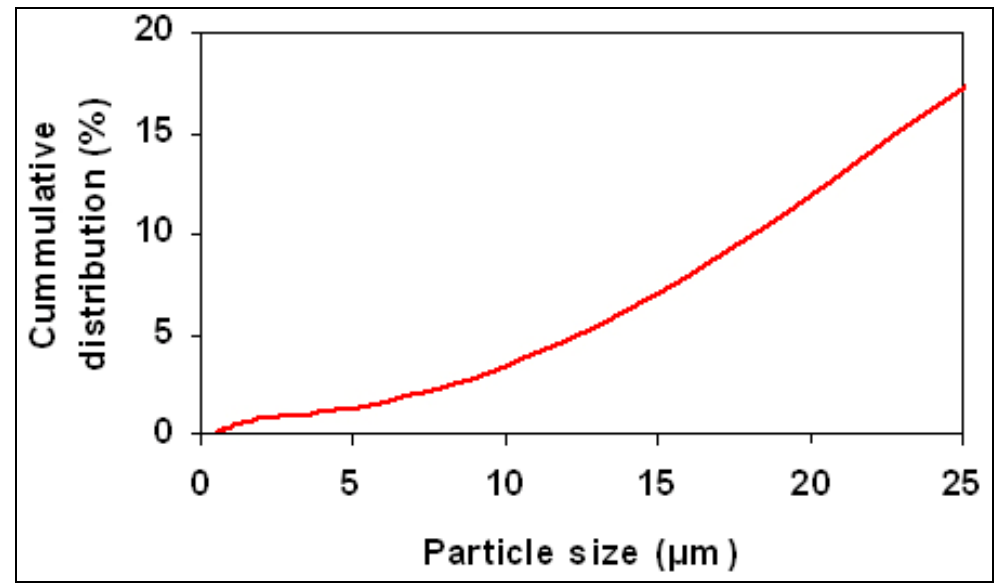

Figure 9 . Cumulative particle size distribution of the mesophilic sludge. 